\title{
Exercise to prevent falls in older adults: an updated meta-analysis and best practice recommendations
}

\author{
Catherine Sherrington $^{\mathrm{A}, \mathrm{B}, \mathrm{E}}$, Anne Tiedemann ${ }^{\mathrm{A}, \mathrm{B}}$, \\ Nicola Fairhall ${ }^{\mathrm{A}, \mathrm{C}}$, Jacqueline C.T. Close $\mathrm{B}^{\mathrm{B}, \mathrm{D}}$ \\ and Stephen R. Lord ${ }^{\mathrm{B}}$ \\ ${ }^{\mathrm{A}}$ Musculoskeletal Division, The George Institute for Global Health, \\ The University of Sydney \\ ${ }^{\mathrm{B}}$ Falls and Balance Research Group, Neuroscience Research \\ Australia, The University of New South Wales \\ ${ }^{\mathrm{C}}$ Rehabilitation Studies Unit, Sydney Medical School, \\ The University of Sydney \\ ${ }^{\mathrm{D}}$ Prince of Wales Hospital Clinical School, The University \\ of New South Wales \\ ${ }^{\mathrm{E}}$ Corresponding author.Email: csherrington@georgeinstitute. \\ org.au
}

\begin{abstract}
This systematic review update includes 54 randomised controlled trials and confirms that exercise as a single intervention can prevent falls (pooled rate ratio $0.84,95 \%$ CI $0.77-0.91$ ). Metaregression revealed programs that included balance training, contained a higher dose of exercise and did not include walking training to have the greatest effect on reducing falls. We therefore recommend that exercise for falls prevention should provide a moderate or high challenge to balance and be undertaken for at least 2 hours per week on an ongoing basis. Additionally, we recommend that: falls prevention exercise should target both the general community and those at high risk for falls; exercise may be undertaken in a group or home-based setting; strength and walking training may be included in addition to balance training but high risk individuals should not be prescribed brisk walking programs; and other health-related risk factors should also be addressed.
\end{abstract}

The prevention of falls and mobility-related disability among older people is an urgent public health challenge in Australia and internationally. Falls and fractures already have a major impact on older individuals, their carers, health services and the community. This impact will grow substantially in the near future due to the increased proportion of older people in the population. The proportion of Australians aged 65 years and over is predicted to increase from $14 \%$ ( 3 million people) in 2010 to $23 \%$ (8.1 million people) by $2050 .{ }^{1}$ By 2051 , the Australian total annual health costs from fall-related injury are predicted to increase almost threefold to $\$ 1.4$ billion. $^{2}$

Many older individuals and their families are affected by falls. One-third of people aged 65 years and over fall once or more annually. ${ }^{3}$ Falls can result in injuries, a loss of confidence and a subsequent reduction in physical activity and community participation. Falls are associated with a threefold increase in the risk of being admitted to a residential aged-care facility after adjusting for other risk factors. ${ }^{4}$

\section{Exercise can prevent falls}

Trials and systematic reviews ${ }^{5,6}$ now provide clear evidence that falls in older people can be prevented with appropriately designed intervention programs. The recently updated Cochrane systematic review ${ }^{5}$ concluded that exercise interventions reduce the risk and rate of falls. Although many risk factors for falls have been identified, ${ }^{7}$ intervention trials have found that the effects of exercise as a single falls prevention intervention are comparable to those from multifaceted interventions. ${ }^{5,8}$ Therefore, widespread implementation of exercise as a single intervention seems to be the best approach to falls prevention at a population level. Our previous meta-analysis ${ }^{6}$ found that up to $42 \%$ of falls can be prevented by well-designed exercise programs and that the exercises which had the biggest effect on fall rates involved a challenge to balance abilities and were undertaken frequently (e.g. for more than 2 hours a week over a 6-month period).

Both home-based and group-based programs have been shown to prevent falls. ${ }^{5,6}$ Group-based Tai Chi has been found to be effective for falls prevention in several trials. ${ }^{9,10}$ Other well-designed group-based interventions can also prevent falls. ${ }^{11,12}$ The availability of home-based programs is also important as many older people are reluctant to or unable to attend group exercise classes. ${ }^{13}$ The home-based Otago Exercise Programme has been shown to reduce rates of falls and injurious falls by $35 \% .{ }^{14}$ It involves five home visits from a physiotherapist 


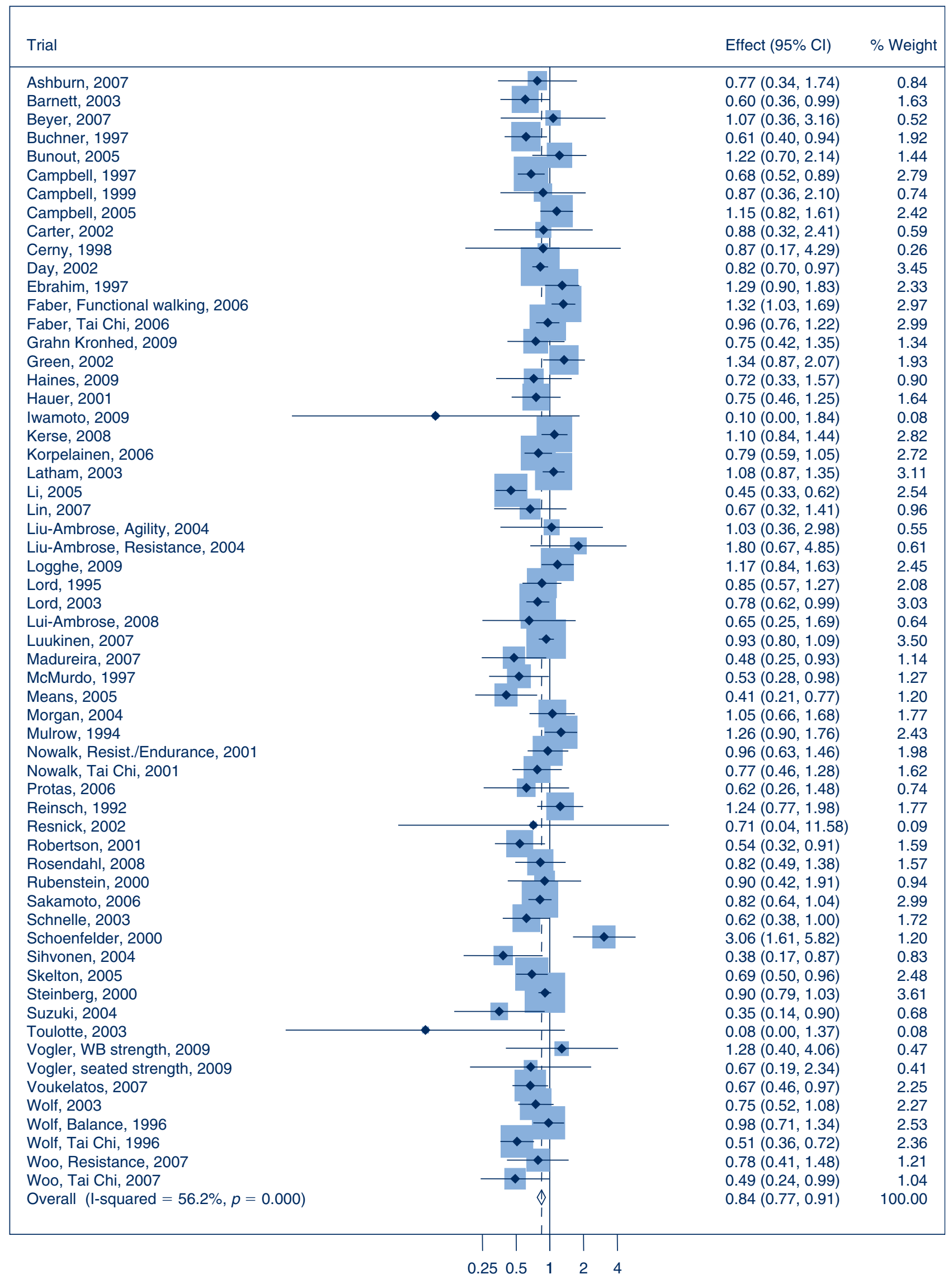

Favours exercise

Favours control

Figure 1. Summary of meta-analysis results: forest plot showing effects of exercise on fall rates in individual trials and the pooled effects of exercise on fall rates. 
or trained nurse to teach exercises to be undertaken at home and monthly phone calls to encourage ongoing adherence. As this program requires a relatively small investment to implement (approximately $\$ 1000$ per person $^{15}$ ) it appears to be a cost-effective approach to falls prevention. ${ }^{16,17}$ As a result, this program was implemented across New Zealand by the Accident Compensation Corporation.

\section{Updated systematic review: methods}

We updated our previously published systematic review using the same approach to searching electronic databases used in the original review. ${ }^{6}$ For this update, databases were searched up to May 2010. The methodology used in the original review ${ }^{6}$ was then used to determine whether studies were eligible for inclusion in this updated review, extract falls data, code the components of exercise programs and combine data in a meta-analysis. We undertook metaregression analysis to establish whether the inclusion of different features of the exercise programs tested explained the variability between the study findings. We tested the features found to be associated with different effects in our previous analysis ${ }^{6}$ (exercise which challenged balance, higher dose of exercise, inclusion of a walking program, trial conducted on a high risk population). Details of these methods are given in our original publication on this metaanalysis. ${ }^{6}$ For this update we also conducted an exploratory analysis which only included the trials conducted in residential care settings.

\section{Updated systematic review: results}

Ten additional eligible trials were included in this update of our meta-analysis. The findings of the meta-analysis remain essentially unchanged. The pooled estimate of the effect of exercise on the rate of falls indicates a $16 \%$ reduction (pooled rate ratio from random effects metaanalysis $0.84,95 \%$ CI $0.77-0.91,54$ trials). The estimates of the effect of exercise on falls from each of the individual trials are shown in the forest plot in Figure 1. There was a moderate amount of variability between the findings of the included trials $\left(I^{2}=56 \%\right)$. The updated meta-regression analysis confirmed that features of exercise program design and trial population can explain some of this between-trial variability. As Table 1 outlines, the programs that included balance training, a higher dose of exercise and did not include walking training had the greatest effect on reducing falls. The effect on falls of programs with and without these features is also shown in Table 1. Table 2 shows the effect on falls of different combinations of features. Two-thirds (64\%) of the variability between different findings of included trials was explained by the inclusion of balance training, a higher dose of exercise and walking training. However, trials with and without walking training led to a reduction in falls if they also included balance training and a high dose of exercise.

The exploratory meta-analysis which included only the 15 comparisons from trials conducted in residential care settings found that exercise resulted in a $7 \%$ reduction in

Table 1. Summary of meta-analysis results: reductions in falls from exercise programs with different components

\begin{tabular}{|c|c|c|c|c|c|c|c|}
\hline \multirow[t]{2}{*}{ Component } & \multicolumn{3}{|c|}{$\begin{array}{l}\text { Reduction in falls in studies } \\
\text { with this component }\end{array}$} & \multicolumn{3}{|c|}{$\begin{array}{l}\text { Reduction in falls in studies } \\
\text { without this component }\end{array}$} & \multirow{2}{*}{$\begin{array}{c}\text { Variability } \\
\text { explained } \\
\text { (\%) }\end{array}$} \\
\hline & $\begin{array}{l}\text { Reduction } \\
\%\end{array}$ & $95 \% \mathrm{Cl}$ & $\begin{array}{c}\text { Studies } \\
n\end{array}$ & $\begin{array}{l}\text { Reduction } \\
\%\end{array}$ & $95 \% \mathrm{Cl}$ & $\begin{array}{c}\text { Studies } \\
n\end{array}$ & \\
\hline $\begin{array}{l}\text { Exercise that aims to provide a } \\
\text { moderate or high challenge to balance }\end{array}$ & 22 & $14-30$ & 43 & 0 & $0-14$ & 17 & 15 \\
\hline $\begin{array}{l}\text { Exercise that aims to provide a high } \\
\text { challenge to balance }\end{array}$ & 25 & $15-34$ & 30 & 6 & $0-17$ & 30 & 16 \\
\hline Total exercise dose more than 50 hours & 23 & $13-32$ & 30 & 7 & $0-8$ & 30 & 19 \\
\hline Inclusion of walking training & 10 & $0-22$ & 30 & 23 & $11-32$ & 30 & 8 \\
\hline A high risk study population & 10 & $0-20$ & 39 & 27 & $14-37$ & 21 & 15 \\
\hline
\end{tabular}

Table 2. Summary of meta-analysis results: reductions in falls from exercise programs with different combinations of components

\begin{tabular}{lccc}
\hline Component & $\begin{array}{c}\text { Reduction in falls in studies with this combination of } \\
\text { components } \\
95 \% \mathrm{Cl}\end{array}$ & $\begin{array}{c}\text { Reduction } \\
\%\end{array}$ & $\begin{array}{c}\text { Studies } \\
n\end{array}$ \\
\hline Balance training, no walking training and a higher exercise dose & 38 & $27-46$ & 8 \\
Balance training, walking training and a higher exercise dose & 21 & $11-30$ & 14 \\
\hline $\mathrm{Cl}=$ confidence interval. & & \\
\hline
\end{tabular}


fall rates (rate ratio $0.93,95 \%$ CI $0.78-1.11$ ) which was not statistically significant $(p=0.446)$. However, the features of exercise programs which were associated with bigger reductions in falls in all the trials were also associated with bigger effects in the residential care trials. The reductions in falls in studies in which interventions provided a challenge to balance, a high dose of exercise and no walking program were close to being statistically significant (rate ratio 0.64 , $95 \%$ CI $0.40-1.02, p=0.057$ ). Further trials are required in residential aged care to clarify the effect of exercise but we suggest that, at this stage, the following recommendations also apply to people in residential aged care.

Few trials have been conducted specifically in people with cognitive impairment yet it is likely that many individuals with cognitive impairment participated in the trials included in this review. Thus we also suggest that, at this stage, the recommendations also apply to people with cognitive impairment.

Modification of implementation approaches are required to ensure safety and efficacy of exercise interventions in residential care settings and for those with cognitive impairment.

\section{Best practice recommendations}

On the basis of the updated systematic review we have formulated the following best practice recommendations to guide the use of exercise for falls prevention.

\section{Recommendation 1. Exercise must provide a moderate or high challenge to balance}

Table 1 shows that programs which do not aim to challenge balance are not effective in preventing falls.

Exercises should aim to challenge balance in three ways:

1. Reducing the base of support (e.g. standing with both legs close together, standing with one foot directly in front of the other, i.e. a tandem stance position and, if possible, standing on one leg).

2. Movement of the centre of gravity - control of the body's position while standing (e.g. reaching safely, transferring the body weight from one leg to the other, stepping up onto a block).

3. Reducing the need for upper limb support with exercises in standing that do not use the arms for support. If this is not possible the aim should be to decrease reliance on the arms (e.g. hold onto a bar with one hand instead of both hands, rest one finger on a table rather than the whole hand).

Care should be taken with exercise to challenge balance to ensure it is carried out in a manner that does not increase the risk of falling.

\section{Recommendation 2. Exercise must be of a sufficient dose} to have an effect

Table 1 shows that there were bigger effects on falls from programs that involved a higher dose of exercise. For the analysis we used a cut-off of 50 hours over the trial period to dichotomise the total prescribed dose of exercise in the included trials into 'high' and 'low' dose. This would equate to around 2 hours a week for a 6-month period. However, the literature does not provide a clear cut-off and there is an indication from other sources ${ }^{18}$ that there are greater benefits from higher doses of exercise. Therefore we suggest that exercise should be undertaken for at least 2 hours per week. This can include a mixture of groupbased and home-based exercise.

\section{Recommendation 3. Ongoing exercise is necessary}

Unfortunately, the benefits of exercise are rapidly lost when exercise is ceased. Therefore ongoing exercise would be necessary for a lasting falls prevention effect.

Recommendation 4. Falls prevention exercise should be targeted at the general community as well as those at high risk for falls

Table 1 shows that the trials to date have found a larger relative effect from programs offered to the general community than programs offered to high risk groups. Yet high risk groups actually have more falls so a greater number of falls can be prevented in this population. Different groups of people will require different exercise delivery strategies. For example, those at higher risk may require smaller group sizes and closer supervision.

\section{Recommendation 5. Falls prevention exercise may be} undertaken in a group or home-based setting

Exercise can prevent falls when delivered in a group or home-based setting. Some individuals are likely to prefer one or the other and we suggest that both options be available. The supplementation of group sessions with additional home-based exercise is a strategy used in several of the effective trials. ${ }^{11}$

\section{Recommendation 6. Walking training may be included} in addition to balance training but high risk individuals should not be prescribed brisk walking programs

Table 1 shows that programs both with and without walking training were effective in preventing falls, yet the inclusion of walking training in the falls prevention programs was associated with a lesser effect on falls. We suggest that the inclusion of walking training may not be a crucial feature of program design and therefore recommend that walking training be included in a program as long as it is not at the expense of balance training. 
One trial found that prescription of fast walking programs for people at high risk of falls can increase the rate of falls. ${ }^{19}$ However, there are many health benefits of physical activity. ${ }^{20}$ The Otago Exercise Programme can be effective in preventing falls and includes the prescription of a walking program if the exercise provider considers the individual participant to be safely able to undertake such a program. We suggest that this approach be used for participants in falls prevention exercise programs.

\section{Recommendation 7. Strength training may be included in addition to balance training}

Although the inclusion of strength training does not seem to be crucial for an effect of exercise on falls, there are many benefits from strength training. ${ }^{20}$ As reduced muscle strength is an important risk factor for falls ${ }^{21}$ there may also be longer-term falls prevention benefits from strength training which are not detected in falls trials with relatively short follow-up periods. To be effective, strength training needs to overload the muscles by providing an amount of resistance (e.g. with a weight or exercise band) that ensures that an exercise can only be done 10-15 times before muscles fatigue. ${ }^{20}$

\section{Recommendation 8. Exercise providers should make referrals for other risk factors to be addressed}

This review focuses on exercise as a single falls prevention intervention. There is also evidence that multifaceted intervention programs can prevent falls and that nonexercise-based single interventions can prevent falls in people with particular risk factors. ${ }^{5}$ Trials included in the Cochrane review ${ }^{5}$ have found that: cataract surgery can prevent falls in people with cataracts; home safety advice and modification are effective in higher risk people; psychoactive medication reduction can prevent falls; and cardiac pacemaker insertion has a role in some individuals. A recent trial also found that the use of single lens rather than multifocal glasses can prevent falls in people who regularly participate in outdoor activites. ${ }^{22}$ We suggest that exercise providers be made aware of these risk factors and evidence-based interventions and suggest that older people affected by one or more of these risk factors receive a full assessment at a falls clinic or ask their general practitioner for appropriate referrals.

\section{Conclusion}

This updated systematic review confirms that exercise as a single intervention can prevent falls. This review includes sufficient trials to allow the development of best practice guidelines which highlight features of exercise programs which are likely to be associated with greater falls prevention effects. The widespread implementation of these recommendations presents an important and urgent challenge for health policy and practice.

\section{Acknowledgments}

C Sherrington, A Tiedemann and SR Lord are funded by National Health and Medical Research Council Fellowships. N Fairhall is funded by a scholarship from a National Health and Medical Research Council Health Services Research Grant.

\section{References}

1. Australia to 2050: future challenges. The 2010 Intergenerational Report. Canberra: Commonwealth of Australia; 2010.

2. Moller J. Projected costs of fall related injury to older persons due to demographic change in Australia: report to the Commonwealth Department of Health and Ageing. Canberra: New Directions in Health and Safety; 2003.

3. Lord SR, Ward JA, Williams P, Anstey KJ. An epidemiological study of falls in older community-dwelling women: the Randwick falls and fractures study. Aust J Public Health 1993; 17(3): 240-5. doi:10.1111/j.1753-6405.1993.tb00143.x

4. Tinetti ME, Williams CS. Falls, injuries due to falls, and the risk of admission to a nursing home. N Engl J Med 1997; 337(18): 1279-84. doi:10.1056/NEJM199710303371806

5. Gillespie LD, Robertson MC, Gillespie WJ, Lamb SE, Gates S, Cumming RG et al. Interventions for preventing falls in older people living in the community. Cochrane Database Syst Rev 2009; CD007146.

6. Sherrington C, Whitney JC, Lord SR, Herbert RD, Cumming $\mathrm{RG}$, Close JC. Effective exercise for the prevention of falls: a systematic review and meta-analysis. J Am Geriatr Soc 2008; 56(12): 2234-43. doi:10.1111/j.1532-5415.2008.02014.x

7. Lord SR, Sherrington C, Menz HB, Close JCT. Falls in older people: risk factors and strategies for prevention. 2nd ed. Cambridge: Cambridge University Press; 2006.

8. Campbell AJ, Robertson MC. Rethinking individual and community fall prevention strategies: a meta-regression comparing single and multifactorial interventions. Age Ageing 2007; 36(6): 656-62. doi:10.1093/ageing/afm 122

9. Voukelatos A, Cumming RG, Lord SR, Rissel C. A randomized, controlled trial of tai chi for the prevention of falls: the Central Sydney tai chi trial. J Am Geriatr Soc 2007; 55(8): 1185-91. doi:10.1111/j.1532-5415.2007.01244.x

10. Wolf SL, Barnhart HX, Kutner NG, McNeely E, Coogler C, $\mathrm{Xu} \mathrm{T}$. Reducing frailty and falls in older persons: an investigation of Tai Chi and computerized balance training. Atlanta FICSIT Group. Frailty and Injuries: Cooperative Studies of Intervention Techniques. J Am Geriatr Soc 1996; 44(5): 489-97.

11. Barnett A, Smith B, Lord SR, Williams M, Baumand A. Community-based group exercise improves balance and reduces falls in at-risk older people: a randomised controlled trial. Age Ageing 2003; 32(4): 407-14. doi:10.1093/ageing/32.4.407

12. Skelton D, Dinan S, Campbell M, Rutherford O. Tailored group exercise (Falls Management Exercise - FaME) reduces falls in community-dwelling older frequent fallers (an RCT). Age Ageing 2005; 34(6): 636-9. doi:10.1093/ageing/afi174

13. Yardley L, Bishop FL, Beyer N, Hauer K, Kempen GI, PiotZiegler $\mathrm{C}$ et al. Older people's views of falls-prevention interventions in six European countries. Gerontologist 2006; 46(5): 650-60.

14. Robertson MC, Campbell AJ, Gardner MM, Devlin N. Preventing injuries in older people by preventing falls: 
a meta-analysis of individual-level data. J Am Geriatr Soc 2002; 50(5): 905-11. doi:10.1046/j.1532-5415.2002.50218.x

15. Day L, Hoareau E, Finch C, Harrison J, Segal L, Bolton T et al. Modelling the impact, costs and benefits of falls prevention measures to support policy-makers and program planners. Monash University Accident Research Centre; 2009.

16. Davis JC, Robertson MC, Ashe MC, Liu-Ambrose T, Khan KM, Marra CA. Does a home-based strength and balance programme in people aged $>$ or $=80$ years provide the best value for money to prevent falls? A systematic review of economic evaluations of falls prevention interventions. Br J Sports Med 2010; 44(2): 80-9. doi:10.1136/bjsm.2008.060988

17. Hektoen LF, Aas E, Luras H. Cost-effectiveness in fall prevention for older women. Scand J Public Health 2009; 37(6): 584-9. doi:10.1177/1403494809341093

18. Nelson ME, Rejeski WJ, Blair SN, Duncan PW, Judge JO, King $\mathrm{AC}$ et al. Physical activity and public health in older adults: recommendation from the American College of Sports Medicine and the American Heart Association. Med Sci Sports Exerc 2007; 39(8): 1435-45. doi:10.1249/mss.0b013e3180616aa2

19. Ebrahim S, Thompson PW, Baskaran V, Evans K. Randomized placebo-controlled trial of brisk walking in the prevention of postmenopausal osteoporosis. Age Ageing 1997; 26(4): 253-60. doi:10.1093/ageing/26.4.253

20. American College of Sports Medicine position stand. Exercise and physical activity for older adults. Med Sci Sports Exerc 2009; 30(6): 992-1008.

21. Moreland JD, Richardson JA, Goldsmith CH, Clase CM. Muscle weakness and falls in older adults: a systematic review and meta-analysis. J Am Geriatr Soc 2004; 52(7): 1121-9. doi:10.1111/j.1532-5415.2004.52310.x

22. Haran MJ, Cameron ID, Ivers RQ, Simpson JM, Lee BB, Tanzer $\mathrm{M}$ et al. Effect on falls of providing single lens distance vision glasses to multifocal glasses wearers: VISIBLE randomised controlled trial. BMJ 2010; 340: c2265. doi:10.1136/bmj.c2265 